\title{
PERFIL DO "TEACHERPRENEUR" PROFESSOR EMPREENDEDOR NAS ENGENHARIAS
}

DOI: 10.37702/2175-957X.COBENGE.2021.3519

JORGE CANDIDO - j_candido@uol.com.br

UNIVERSIDADE TECNOLOGICA FEDERAL DO PARANÁ

Rua Rocha Pombo 1693

87303-220 - Campo Mourão - PR

Genilson Valotto Patuzzo - genilson.valotto@gmail.com

UTFPR

RUA IGNACIO TROMBINI, 232

87301-200 - Campo Mourão - PR

Gilmar Barreto - gbarreto@dsif.fee.unicamp.br

Universidade Estadual de Campinas

Avenida Albert Einstein 400

13083-852 - Campinas - SP

Paulo César de Resende Andrade - paulo.andrade@ict.ufvjm.edu.br

Universidade Federal dos Vales do Jequitinhonha e Mucuri

Rua Heloísa Durães Neves 36

39100-000 - Diamantina - MG

Resumo: $O$ futuro da educação em engenharia está pendente de uma mudança urgente. O professor é o principal vetor para essa mudança, pois ocupa um lugar de destaque nas práticas educacionais atuais, haja vista a necessidade de construção de novos modelos de formação e de renovação no perfil e o papel deste professor empreendedor - teacherpreneur. O objetivo deste trabalho é apresentar o perfil necessário do "novo professor" em resposta as diretrizes curriculares nacionais que almejam um novo perfil do egresso. Mudar as matrizes curriculares dos cursos das engenharias traz resultados, é necessário mudar a postura do professor em sala de aula, com perfil inovador, transformador, colaborativo e resolver problemas complexos. Principalmente transladando conhecimentos além dos conteúdos programáticos como valores e habilidades necessárias para a nova era empresarial. Oferecendo uma experiência de aprendizado única que agregará à sua carreira profissional. 


\section{(C. COBENGE de Educação em Engenharia 2021 de Educação 28 a 30 de SETEMBRO

Palavras-chave: Professor Empreendedor, Perfil do Professor, Professor Inovador, Novo Professor, Professor Empreendedor 


\section{PERFIL DO "TEACHERPRENEUR" PROFESSOR EMPREENDEDOR NAS ENGENHARIAS}

\section{INTRODUÇÃO}

Desde abril de 2019 com a homologação da resolução oㅡ 2 que institui as Diretrizes Curriculares Nacionais do Curso de Graduação em Engenharia (DCNs) (MEC, 2019) tem se discutido veemente o novo perfil e as novas competências do egresso em engenharia $\mathrm{e}$ principalmente pautada na educação empreendedora.

Pensar no papel deste novo engenheiro para com a sociedade é pensar muito além do tradicional. Este novo engenheiro, além de um amplo conhecimento tecnológico, sendo esta, uma condição sine qua non para ingressar no mercado profissional, deverá também dominar outras competências, como saber conviver com incertezas, ser ético na sua profissão e com as pessoas, desenvolver o espírito empreendedor e o pensamento crítico, e acima de tudo, compreender as mudanças sociais e ambientais que estão ocorrendo simultaneamente (CANDIDO et al, 2017).

No entanto, as mudanças que ocorrem na sociedade e que determinam a condução do modelo de formação tradicional, geram a necessidade de redefinir o papel do professor e, consequentemente, de propor novas alternativas para sua formação e desenvolvimento profissional.

A necessidade de um novo perfil do egresso em engenharia carrega em si uma mudança do papel e perfil do professor. Este que ocupa lugar de destaque nas práticas educacionais atuais, haja vista a necessidade de construção de novos modelos de formação e de renovação no perfil e o papel deste "novo professor". Pois passaram a configurar uma longa lista de "competências desejáveis" dos egressos nas quais convergem para postulados derivados de abordagens eficientes da educação.

O panorama educacional do mundo de hoje, em escolas e Instituições de Ensino Superior (IES), passam por mudanças profundas em seus métodos, conteúdos e espaços de aprendizagem. Uma maior oferta e fontes de conhecimentos expandiu as oportunidades de aprendizagem e métodos inovadores. Isso tem "afetado a sala de aula, a pedagogia, a autoridade do professor e os processos de aprendizagem" (UNESCO, 2016, p. 51).

Deste o relatório Delors de 1996, elaborado para a UNESCO, vem tratando-se de uma perspectiva que o "novo professor" deva desenvolver uma pedagogia pautada no diálogo, na articulação entre teoria e prática, na interdisciplinaridade, na diversidade e no trabalho em equipe. Assim a abordagem STEM - Science, Technology, Engineering and Mathematics (Ciência, Tecnologia, Engenharia e Matemática, em português) vem aliada a cultura maker (fazer) e hands-on (mão na massa) tão solicitada pelo mercado.

Dessa forma, o professor estimula a curiosidade e associa com atividades que requerem mais participação dos alunos o tornando mais engajado com os temas de estudo. No entanto, para que isso funcione o professor deve ser mediador e colaborador. E este seja capaz de ter iniciativas e fomentar ideias e projetos inovadores, que desenvolva com a ajuda de seus alunos para apropriarem de conhecimentos, valores e habilidades necessárias para os quatro pilares da educação (aprender a conhecer, a fazer, a ser e a conviver). Consequentemente, incorpora em sua prática docente a gestão de novas tecnologias para o ensino em sala de aula e fora dela e, para a sua própria aprendizagem. Além disso, o professor deve ser visto pelos alunos como um amigo e/ou modelo, alguém que os ouve e os ajude a se desenvolverem (UNESCO, 1996). 
Com base nestas premissas, o "novo professor" deve ser empreendedor teacherpreneur, do acrônimo em inglês (teacher + entrepreneur, ou seja, professor + empreendedor) pois tem que se reinventar todos os "dias", pois a cada semestre ou ano lida com alunos novos e características e necessidades novas, assim como as empresas.

Deste modo, este trabalho tem por objetivo descrever o perfil para o teacherpreneur (professor empreendedor) nas engenharias.

\section{PROFESSOR NO ENSINO SUPERIOR}

O trabalho do professor, na maioria dos casos, materializa-se na ideia de que a profissão de professor se resume em ensinar um conjunto de pessoas para o estabelecimento e legitimação da ciência e cultura. Como cita Cunha (2008) a universidade, com a sua preocupação de universalidade, se constitui como a fortaleza da uniformidade de ordenação da transmissão e globalização dos conteúdos e processos que se revelam, algumas vezes, pouco adequados ao quadro atual em que se insere. Os docentes universitários ensinam geralmente como foram ensinados, garantindo, pela sua prática, uma transmissão mais ou menos eficiente de saberes e uma socialização idêntica àquela de que eles próprios foram objeto.

No ensino de engenharia, a forma como são repassados os conteúdos mantém-se fiel a suas tradições de anos ou mesmo de décadas atrás, o docente de engenharia comporta-se como se habitasse uma esfera única e isolada, que se realimenta através de suas próprias pesquisas e descobertas tecnológicas (CANDIDO, 2019).

Os docentes mesmo com todo avanço das tecnologias de comunicação, se comportam como um grupo único e especializado, isto faz com que se afasta de suas origens e também da realidade de seu dia a dia, criando seus próprios critérios de avaliação e desempenho, por melhor que sejam, tende a desaparecer com o tempo perante aos demais grupos que atuam num mesmo segmento. Aja visto que, muitas das ferramentas utilizadas ainda hoje no ensino de engenharia podem estar desatualizadas, o que corrobora em não conseguir acompanhar rapidamente as mudanças exigidas pela sociedade, (BAZZO; PEREIRA; LINSINGEN, 2008).

Sem embargo, os professores têm um efeito profundo no aprendizado e desempenho dos alunos, e alguns professores são claramente mais eficazes do que outros na promoção de resultados educacionais desejáveis (BARDACH; KLASSEN, 2020).

Dessa forma os processos de emancipação são estimuladores de intervenções compromissadas com as rupturas que atuam no sentido da mudança. Com cita Cunha (2008) que não são medidos pelo tamanho e abrangência, mas sim pela profundidade e significado que tem para os sujeitos envolvidos.

Sem dúvida, a mudança no paradigma do ensino superior, traz a luz a inovação no ensino superior, pois os discentes deste século XXI já não têm mais as características de alguns poucos anos atrás, a busca pela informação, conhecimento e métodos os transformaram.

\subsection{A perspectiva do docente}

A docência como em qualquer outra profissão, exige conhecimentos específicos e técnicos para o exercício da profissão. No entanto, a docência vai além das necessidades exigidas pelos profissionais de cada área. Como salienta Lawler (2003), que muitas profissões demandam a formação especifica e entidades de classes emitem registros para atuação profissional para que o indivíduo possa exercer sua profissão, embora, isto não acontece com a carreira do professor universitário, pois normalmente a formação técnica 
em nível superior e alguma habilidade de comunicação são os subsídios mais influenciadores no ingresso da carreira docente.

Mas estas competências são suficientes para o desempenho da profissão e cumprir com as DCNs atuais? Essa é uma reflexão muito importante para os professores, pois o ensino e aprendizagem vem evoluindo de forma acelerada e muitos docentes não tem acompanhado tal evolução. Pois não basta ter um mestrado ou doutorado conforme recomendações do MEC (1996) e sim competências e habilidades que vão além da sala de aula e do conhecimento técnico.

Como já citado, muitos professores ensinam como foram ensinados, garantindo, pela sua prática, uma transmissão mais ou menos eficiente de saberes e uma socialização idêntica àquela de que eles próprios foram objeto e essa prática em sua maioria já não é válida.

Os métodos de ensino e aprendizagem estão mudando de maneira muito rápida, principalmente com a advento da tecnologia no ambiente acadêmico. $E$ as DCNs estão buscando que os professores se desenvolvam como profissionais da docência, além das competências técnicas.

A formação docente deve ser vista como um processo contínuo, tal que seja disponibilizado a esse profissional um espaço para discutir e refletir sua formação inicial, assim como o seu aperfeiçoamento continuado. A questão da formação docente não se deve restringir apenas a um esforço das IES em conseguir formar um docente para os cursos das engenharias, deve sim, ser vista pelo docente como um processo em que o maior interessado é ele próprio, o docente, afim de que ele possa analisar as suas práticas pedagógicas utilizadas, o seu desenvolvimento e o resultado em sala de aula. (VILELA, 2016). Onde se faz necessário que o professor tenha, além das técnicas, competências pedagógicas e didáticas, ou de ensino e aprendizagem, sobrepujando os feitios conceituais e práticos do profissional docente (AKERLIND, 2003, KELCHTERMANS, 2009).

Esta perspectiva se reflete no conceito de "capital profissional" desenvolvido por Hargreaves e Fullan:

Um bom ensino para todos os alunos exige que os professores sejam altamente comprometidos, totalmente preparados, desenvolvidos continuamente, bem pagos e bem conectados uns com os outros para maximizar sua própria melhoria, e capazes de fazer julgamentos eficazes usando todas as suas capacidades e experiência ${ }^{1}$ (Hargreaves; Fullan, 2012, p. 3).

\section{PERFIL DO PROFESSOR UNIVERSITÁRIO}

A discussão sobre o perfil do professor universitário é longa e pode ser feita sobre várias perspectivas. No entanto, sobre a forma de ensinar, deve ser realizada constantemente reflexões em especial na era da revolução industrial 4.0 e da sociedade 5.0, a era da ruptura tecnológica e de sistemas físicos cibernéticos, e melhorar a qualidade dos recursos humanos é a preocupação em todos os países (BUCKLEY; FUTONGE, 2016). Pois, ainda que ocorra a conexão da automatização e tecnologias digitais simultâneas, continua havendo a necessidade de pessoas qualificadas no trabalho, exigindo novas competências e habilidades.

Esta nova era, transcende o espaço empresarial, pois para que haja o desenvolvimento destas novas competências e habilidades, há a necessidade de se iniciar nos locais de ensino e principalmente no nível superior. Berry (2011), em seu livro Teaching

${ }^{1}$ Tradução livre dos autores 
2030: What We Must Do for Our Students and Our Public Schools - Now and in the Future, prevê os acontecimentos vivenciados pelos professores e a necessidade de novos conhecimentos e habilidade de alunos que nunca aprenderam com os professores antes.

Isto abre caminho/necessidades para que os professores tenham que aprender a aprender a lidar com as novas necessidades do mundo profissional e também da nova geração de pessoas os millennials, que conforme cita Pinto (2019), essa geração tem perfil diferente das gerações anteriores como: liberdade de expressão; flexibilidade; interatividade; sentimento de que são especiais; preferência por trabalhos em grupo; dificuldade de manter a atenção em apenas uma atividades; confiança em fazer diversas coisas ao mesmo tempo; incompatibilidade com modelos de aulas tradicionais; predileção por aulas práticas; proximidade com figuras de autoridade nas quais podem se espelhar; uso da tecnologia e preferência por comunicação por mensagens instantâneas. Assim, as competências e habilidades dos professores deixam de ser somente tecnicistas e passa a exigir uma competência profissional complexa.

Segundo Araújo; Bernuy e Patuzzo (2019) a utilização de novas tecnologias pode contribuir de maneira efetiva para o avanço técnico e científico, o aumento da inclusão social e melhoria da qualidade de vida das pessoas, abrindo espaço para novas profissões e novas formas de empregabilidade. Para que isso aconteça, é necessário que as pessoas mudem a sua forma de pensar e agir, desenvolvam suas habilidades cognitivas, sejam resilientes, inovadoras e se adaptem às mudanças ocasionadas pela Globalização 4.0 à medida que elas ocorrem.

E diante desta complexidade exigida, o professor empreendedor passa a ser de extrema relevância devido a características típicas do empreendedorismo e da carreira de professor.

O professor na antiguidade, no início das civilizações, era a figura de alguém com experiência em algo (caçar, pescar, lutar, etc) e este ensinava os mais jovens a se prepararem para a vida. Transladando para a nossa época não é diferente, pois temos que preparar os alunos para o mercado de trabalho. No entanto, este cada vez mais complexo e cheios de incertezas.

Estas incertezas que o escritor Richard Cantillon em sua obra de 1755 - Ensaio sobre a natureza do comércio em geral, usou pela primeira vez o termo empreendedor em um contexto econômico para se referir a um indivíduo que assume riscos em condições de incertezas e que inclusive tem ganhos incertos (CANTILLON, 2002). No entanto, o pensamento mais contemporâneo desenvolvido por Schumpeter (1963), descreve os empreendedores como inovadores e criadores. Martes (2010, p. 255) expõe o empreendedor de Schumpeter como um "tipo especifico de agente, diferente do mero capitalista, pois ele decide racionalmente com base em valores (inovação), mas que também é guiado pela paixão (desejos e conquistas) e é, necessariamente, um líder".

O "pai" da administração moderna Drucker (1986) tem uma visão mais comportamental e psiossociológica do empreendedor, onde o define como o indivíduo que busca mudanças, responde a elas e as explora como uma oportunidade. Aprofunda-se no argumento sugerindo que aqueles que tem maior resiliência sob as incertezas e podem aprender a se tornar empreendedores. Ou seja, os empreendedores respondem aos incentivos e oportunidades oferecidos por seu ambiente.

Neste ambiente competitivo e inovador, o papel do docente das engenharias é fundamental para realizar essa mudança de comportamento ao discente. Logo o perfil do docente dos cursos das engenharias, necessariamente passa por mudanças nas IES e na cultura enraizada dos docentes dos cursos superiores, que possui como pressuposto que ensinar é somente repassar o conteúdo previamente organizado. Para Gibb (2002), destaca que a cultura empreendedora deve ser fomentada no âmbito de toda instituição entre corpo 
docente e discente. A cultura empreendedora quando bem implementada abre e define caminhos para novas mudanças, como; mudanças de atitudes, estruturas, modelos organizacionais e novos modelos de negócios.

\subsection{Teacherpreneur}

Mudar somente a matriz curricular dos cursos das engenharias, talvez resulte pouco benefício para o futuro profissional que esperamos, é necessário mudar também a postura do professor em sala de aula. Ele precisa estar atento as novas tecnologias disponíveis no mercado e, fazer uso destas no seu dia a dia em sala de aula, inovando na sua prática cotidiana, como resultado, teremos um aluno mais motivado (CANDIDO, 2019).

Neste contexto, os professores devem agir de forma empreendedora conseguir vislumbrar as mudanças do seu meio e se adaptarem a ele. Berry; Byrd e Wieder (2013) salienta que os teacherpreneurs encontram soluções inovadores para os desafios enfrentados pelo setor da educação e estes lideram a mudança em vez de ficarem na mesma dinâmica e tem uma capacidade de administrar melhor os riscos e ser inovador.

Dessa forma podemos salientar que o professor empreendedor é aquele agente transformador, auxiliado por novas tecnologias, ajudará a fazer a mudança na sala de aula e concomitantemente resolver problemas, desde os mais simples aos complexos, e principalmente formando um aluno com conhecimento (valores e habilidades) necessárias para a nova era empresarial. Com isso, oferecem uma nova experiência de aprendizado.

\subsection{Perfil do teacherpreneur}

O perfil esperado deste professor, para o contexto dos cursos das engenharias, obrigatoriamente leva a um novo patamar a ser alcançado. Além de um amplo conhecimento profissional, esse docente necessita desenvolver outras habilidades que 0 capacitem a transformar conhecimentos em negócios. Sobre este aspecto Fillion (1993) descreve algumas características que define uma pessoa empreendedora, um metamodelo empreendedor foi proposto e, descreve as principais características associadas a um empreendedor que são imprescindíveis a este docente:

Quadro 1 - Metamodelo empreendedor

\begin{tabular}{|l|l|}
\hline Metamodelo Empreendedor & Principais Características Associadas \\
\hline \multirow{2}{*}{ Weltanschauung } & $\begin{array}{l}\text { Lida com incerteza } \\
\text { Problema é uma oportunidade }\end{array}$ \\
\hline \multirow{3}{*}{ Visão } & Buscando Oportunidade \\
\cline { 2 - 2 } & Resolução de problemas criativos \\
\cline { 2 - 2 } & Tomada de decisão \\
\hline \multirow{2}{*}{ Liderança } & $\begin{array}{l}\text { Iniciativas independentes } \\
\text { Persuasão/influenciar outros } \\
\text { Gestão interdependente de sucesso }\end{array}$ \\
\hline Energia & Fazer as coisas acontecerem \\
\hline Networking & $\begin{array}{l}\text { Resposta flexível de sucesso } \\
\text { Apresentação segura }\end{array}$ \\
\hline
\end{tabular}

Fonte: Adaptado de Filion (1993)

Em termos gerais, segundo Allan (2019), um professor-empreendedor deve se envolver na liderança educacional, escrever seus próprios currículos, pesquisar metodologias educacionais, aprender a usar diferentes tecnologias, criar cursos próprios e disponibilizar gratuitamente em plataformas digitais, educar outros professores e até trabalhar para reformar as políticas educacionais oficiais. 
Esse novo educador tem como característica fundir a imagem do professor inovador com a liderança empreendedora que assume riscos para criar seu próprio lugar no mundo profissional. São pessoas empenhadas em criar uma cultura de criatividade e reflexão na sala de aula, mas que também pensam suas ações para além deste espaço, pois têm consciência de que o aprendizado e lições valiosas não devem ficar restritos aos bancos escolares. Eles geram renovação e entusiasmo, além de experiências mais eficazes e enriquecedoras para todo o sistema educacional. Em certo sentido, eles dão um passo adiante para alcançar um estado de aprendizado mais engajado e simplificado (ALLAN, 2019).

Seguem algumas características essências para tornar-se um professorempreendedor: ter interesse por tecnologia, ser colaborativo, ficar atento às novas tendências, adaptar-se e estar motivado a aprender sempre.

\section{CONSIDERAÇÕES FINAIS}

Partindo do pressuposto que todos os envolvidos no processo de ensino de engenharia deveriam saber exatamente qual é o profissional que se deseja formar e, conhecendo também a realidade do docente que por sua qualificação volta-se para a pesquisa. Faz-se necessário urgentes mudanças no processo de ensino-aprendizagem, a fim de proporcionar melhores condições de aprendizado a esse aluno que almeja ser um engenheiro e não um cientista pesquisador, (CORDEIRO et al, 2008; CANDIDO et al, 2016).

Apesar de várias reformas feitas no ensino superior, as IES ainda não conseguiram se adaptar ao mesmo ritmo que as transformações tecnológicas vêm ocorrendo. No entanto, é necessário preparar as novas gerações de engenheiros para se adaptarem a um mercado de trabalho e a uma economia impregnada de grande incerteza, caracterizada muitas vezes pela inovação técnica, flexibilidade laboral e globalização econômica, (LEITE et al, 2012).

Este artigo apresentou e discutiu as principais características de um teacherpreneur. Considerando que as diretrizes curriculares das engenharias atuais irão exigir dos novos professores as características de um professor empreendedor devemos destacar pontos que consideramos fundamentais: a) domínio da tecnologia, o novo professor precisa ter o poder de inovar elaborando conteúdo das aulas mais criativos e tornando-as mais interativas; b) espírito colaborativo, o novo professor deve utilizar ferramentas online, é compreender que a tecnologia tem o poder de ajudar as pessoas ao seu redor, e contribuir para uma educação melhor e mais inclusiva; c) abertura para novas às tendências, o novo professor deve estar sempre abertos para as novidades tecnológicas e utiliza-las de maneira adequada em sala de aula; d) conhecer o aluno, o novo professor deve estar atento ao perfil de cada aluno e descobrir maneiras de motiva-los para tornar sua aula cada mais atrativa. Estas recomendações simples podem tornar um curso que os alunos irão lembrar para todo sempre.

Abrir-se para a possibilidade de se transformar num professor-empreendedor é importante porque traz um novo olhar sobre o ensino-aprendizado e sobre suas próprias possibilidades como educador e pessoa. A profissão de professor não vai acabar, mas vai se transformar profundamente. 


\section{REFERÊNCIAS}

AKERLIND, G. S. Growing and Developing as a University Teacher--Variation in Meaning. Studies in Higher Education, v. 28, n. 4, p. 375-390. 2003.

ALLAN, Luciana. Por que você precisa se tornar um professor empreendedor? Revista Exame, 14/12/2019. Disponível: https://exame.com/blog/crescer-em-rede/por-que-voceprecisa-se-tornar-um-professor-empreendedor/. Acesso em Acesso em 05 mai. 2021.

ARAUJO, Jalberth F; BERNUY, Miguel A. C.; PATUZZO, Genilson V. Aplicação de motivação, criatividade e taxonomia de Bloom para melhoria da experiência de aprendizagem do estudante de engenharia: um estudo de caso. XLVII Congresso Brasileiro de Educação em Engenharia e II Simpósio Internacional de Educação em Engenharia da ABENGE. Anais. Fortaleza. Disponível em:

http://www.abenge.org.br/sis_artigos.php. Acesso em 05 mai. 2021.

BAZZO, WALTER ANTÔNIO; PEREIRA, LUIZ TEIXEIRA VALE; VON LINSINGEN, IINSINGEN. Educação tecnológica: enfoques para o ensino de engenharia. 2. ed. Florianópolis: Ed. da UFSC, 2008.

BARDACH, L.; KLASSEN, R. M. Smart teachers, successful students? A systematic review of the literature on teachers' cognitive abilities and teacher effectiveness.

Educational Research Review, York, v. 30, p. 1-21, 2020.

BERRY, BARNETT. Teaching 2030: What We Must Do for Our Students and Our Public Schools - Now and in the Future. New York: Teachers College Press, 2011.

BERRY, BARNETT; BYRD, ANNY; WIEDER, ALAN. Teacherpreneurs: innovative teacher who lead but don't leave. San Francisco: Jossey-Bass, 2013.

BUCKLEY, ANTHONY. PAUL; FUTONGE, KISITO. Teacherpreneurs: From Vocation to Innovation. 4th International Conference on Innovation and Entrepreneurship, Toronto, 28-29 April 2016.

CANDIDO, Jorge B.; GILMAR, Camargo; VERASZTO, José T.; VIZCONDE, Estéfano. A formação do professor para o ensino superior: o processo de ensino e aprendizagem para os cursos de engenharia. Fórum da Gestão do Ensino Superior nos Países e Regiões de Língua Portuguesa. Anais. Campinas. Disponível em: https://www.aforges.org/wpcontent/uploads/2016/11/18-Jorge-Candido-et-al_A-Formac_a_o-do-Professor-para-oEnsino-Superior.pdf. Acesso em 05 mai. 2021.

CANDIDO, Jorge B.; GILMAR, Camargo; VERASZTO, José T.; VIZCONDE, Estéfano. Por que a necessidade de se investir na formação docente para os cursos superiores das engenharias? COBENGE, 2017. Anais. Joinville-SC. Disponível em:

http://www.abenge.org.br/sis_artigos.php. Acesso em 05 mai. 2021.

CANDIDO, Jorge. 2019. Contribuições para a Formação Docente em Cursos de Engenharia: Sua Importância e Necessidade. Tese de Doutorado, UNICAMP. Campinas - SP, 2019. 
CANTILLON, RICHARD. Ensaio sobre a natureza do comércio em geral. Tradução de Fani Goldfarb Figueira. Curitiba: Segesta, 2002.

CORDEIRO, J. S.; ALMEIDA, N.N; BROGES, M.N.; DUTRA, S.C.; VALINOTE, O.L.; PAICA, Z.M.C. Um futuro para a educação em Engenharia no Brasil: Desafios e Oportunidades, Revista de Ensino de Engenharia, v.27, n.3 p. 69-82, edição especial 2008.

CUNHA, M.I. Inovações pedagógicas: o desafio da reconfiguração de saberes na docência universitária. Cadernos Pedagogia Universitária USP, São Paulo, setembro 2008. Disponivel em: http://www.prpg.usp.br/attachments/article/640/Caderno_6_PAE.pdf. Acesso em: 23 Set. 2020.

DRUCKER, PETER. Innovation and entreprenership: practice and principles. New York: Harper \& Row, 1986.

FILION, L. J. Visão e Relações: elementos para um metamodelo empreendedor. Revista de Administração de Empresas. São Paulo. 1993. pp. 50-61.

GIBB, A. In pursuit of a new 'enterprise' and 'entrepreneurship' paradigm for learning: creative destruction, new values, new ways of doing things and new combinations of knowledge. International Journal of Management Reviews. 2002. pp. 233-269.

HARGREAVES, ANDY; FULLAN, MICHAEL. Professional capital. New York: Teacher College Press, 2012.

KELCHTERMANS, G. Who I am in how I teach is the message: self-understanding, vulnerability and reflection. Journal Teachers and Teaching: Theory and Practice, v. 15, n. 2, p. 257-272. Routledge. 2009.

LAWLER, P. Teachers as Adult Learners: A New Perspective. Journal New Directions for Adult and Continuing Education, n. 98, 15-22. Wiley Periodicals. 2003.

LEITE, E. F., CARDOSO, F. I. B., FARIAS, E. R. O engenheiro numa universidade empreendedora-desafio ou solução do século XXI? XL Congresso Brasileiro de Ensino de Engenharia, 2012, Anais. Belém. Disponível em:

http://www.abenge.org.br/CobengeAnteriores/2012/artigos/102728.pdf. Acesso em 05 mai. 2021.

MARTES, A.C.B. Weber e Schumpeter: a ação econômica do empreendedor. Revista de Economia Política, v. 30, n. 2, p. 254-270, abril-junho 2010.

MEC, CNE, CES. Resolução CNE/CES no 2, de 24 de abril de 2019. Diretrizes Curriculares Nacionais do Curso de Graduação em Engenharia, 2019.

MEC. Lei das Diretrizes e Bases da Educação. Lei № 9.394, de 20 de dezembro de 1996.

PINTO, D. D. O. Novas competências do professor: como ensinar e aprender com os millennials? Blog Lyceum, Out. 2019. Disponivel em: 
https://blog.lyceum.com.br/habilidades-e-competencias-do-professor/. Acesso em: 12 Out. 2020.

SCHUMPETER, JOSEPH ALOIS. The theory of economic development: an inquiry into profits, capital, credit, interest, and the business cycle. $3^{\text {a }}$. ed. New Youk: Oxford Univ. Press, 1963.

UNESCO. Educação um tesouro a descobrir: relatório para a UNESCO da comissão internacional sobre educação para o século XXI. Tradução de Jose Carlos Eufrázio. Brasília: Cortez Editora, 1996.

UNESCO. Repensar a educação: rumo a um bem comum mundial? Brasília: UNESCO Brasil, 2016.

VILELA, Naiara Sousa. Docência Universitária: Um estudo sobre a experiência da Universidade Federal de Uberlândia na formação de seus professores. 2016.

Dissertação de Mestrado no Programa de Pós-Graduação em Educação da Universidade Federal de Uberlândia - UFU.

\title{
PROFILE OF THE TEACHERPRENEUR IN ENGINEERING
}

\begin{abstract}
:
The future of engineering education awaits urgent change. The teacher is the main vector of this change, since it occupies a prominent place in current educational practices, given the need to build new models of training and renewal in the profile and role of this teacherpreneur. The objective of this work is to present the necessary profile of the "new teacher" in response to the national curricular guidelines that point to a new profile of the graduate. Changing the curricular matrices of engineering courses brings results, it is necessary to change the position of the teacher in the classroom, with an innovative, transformative, collaborative profile and solving complex problems. Mainly transferring knowledge beyond the syllabus as values and skills necessary for the new era of business. Offering a unique learning experience that will add to your professional career.
\end{abstract}

Keywords: Teacherpreneur, Teacher profile, Innovative teacher, New teacher, Entrepreneurial teacher. 